\title{
The transcriptome landscape of the carcinogenic treatment response in the blind mole rat: insights into cancer resistance mechanisms
}

\author{
Robert Altwasser ${ }^{1}$, Arnon Paz ${ }^{1}$, Abraham Korol ${ }^{1,2}$, Irena Manov ${ }^{1}$, Aaron Avivi ${ }^{1}$ and Imad Shams I $^{1,2^{*}}$ (D)
}

\begin{abstract}
Background: Spalax, the blind mole rat, developed an extraordinary cancer resistance during 40 million years of evolution in a subterranean, hypoxic, thus DNA damaging, habitat. In 50 years of Spalax research, no spontaneous cancer development has been observed. The mechanisms underlying this resistance are still not clarified. We investigated the genetic difference between Spalax and mice that might enable the Spalax relative resistance to cancer development. We compared Spalax and mice responses to a treatment with the carcinogen 3Methylcholantrene, as a model to assess Spalax' cancer-resistance.
\end{abstract}

Results: We compared RNA-Seq data of untreated Spalax to Spalax with a tumor and identified a high number of differentially expressed genes. We filtered these genes by their expression in tolerant Spalax that resisted the 3MCA, and in mice, and found 25 genes with a consistent expression pattern in the samples susceptible to cancer among species.

Contrasting the expressed genes in Spalax with benign granulomas to those in Spalax with malignant fibrosarcomas elucidated significant differences in several pathways, mainly related to the extracellular matrix and the immune system. We found a central cluster of ECM genes that differ greatly between conditions. Further analysis of these genes revealed potential microRNA targets.

We also found higher levels of gene expression of some DNA repair pathways in Spalax than in other murines, like the majority of Fanconi Anemia pathway.

Conclusion: The comparison of the treated with the untreated tissue revealed a regulatory complex that might give an answer how Spalax is able to restrict the tumor growth. By remodeling the extracellular matrix, the possible growth is limited, and the proliferation of cancer cells was potentially prevented. We hypothesize that this regulatory cluster plays a major role in the cancer resistance of Spalax. Furthermore, we identified 25 additional candidate genes that showed a distinct expression pattern in untreated or tolerant Spalax compared to animals that developed a developed either a benign or malignant tumor. While further study is necessary, we believe that these genes may serve as candidate markers in cancer detection.

Keywords: Cancer, Fanconi anemia, Spalax, Cancer-resistance, Extracellular matrix

\footnotetext{
*Correspondence: Imad.shams@univ.haifa.ac.il

1 Institute of Evolution, University of Haifa, Haifa, Israel

${ }^{2}$ Department of Evolutionary and Environmental Biology, University of Haifa,

Haifa, Israel
}

(c) The Author(s). 2019 Open Access This article is distributed under the terms of the Creative Commons Attribution 4.0 International License (http://creativecommons.org/licenses/by/4.0/), which permits unrestricted use, distribution, and reproduction in any medium, provided you give appropriate credit to the original author(s) and the source, provide a link to the Creative Commons license, and indicate if changes were made. The Creative Commons Public Domain Dedication waiver (http://creativecommons.org/publicdomain/zero/1.0/) applies to the data made available in this article, unless otherwise stated. 


\section{Background}

The long-lived (> 20 years) subterranean rodent Spalax (genus Spalax ehrenbergi complex) is a solitary inhabitant of sealed underground burrows in the Eastern Mediterranean region [1]. While these tunnels protect the animals from predation and climatic extremes, they are also prone to sharp drops in $\mathrm{O}_{2}$ levels, which can reach $\sim 7 \%$ in the rainy season [2]. During these periods, Spalax performs intensive digging work under low $\mathrm{O}_{2}$ conditions and rapid re-oxygenation. Spalax displays an extraordinary hypoxia tolerance that has evolved over 40 million years of the species existence in habitats with frequent drops in oxygen. In the laboratory, Spalax can survive $3 \% \mathrm{O}_{2}$ levels, which makes it one of the most hypoxia-tolerant animals known [3, 4]. The extraordinary hypoxia tolerance of Spalax is achieved through several morphological and physiological mechanisms of respiration-related genes and their regulation [3-5] including high blood vessel density, which results in a shorter diffusion distance for oxygen and high levels of activity compared to other murine species [3-5].

The mitochondria's increased production of reactive oxygen species has been observed [6] under hypoxia/reoxygenation cycles, which in turn leads to oxidative stress and damage to the DNA. Because hypoxia also causes dNTP depletion and the repression of DNA repair pathways [5] Spalax has fine-tuned various hypoxia-tolerance strategies during its life history, which seems to have driven a large degree of resistance against cancer development in order to allow survival and fitness in its subterranean habitat. Indeed, spontaneous cancer has never been observed during decades of research on Spalax. A key mechanism that contributes to cancer prevention is the high repair capacity constantly high expression of DNA repair and editing machinery, especially genes associated with the Fanconi anemia DNA repair pathway in Spalax $[5,7,8]$. Another notable mechanism is the heparanase alternatively spliced variant, which inhibits extracellular matrix degradation, tumor growth, and metastasis [9].

A previous study has reported that Spalax individuals are predominantly resistant to carcinogenic compound treatment and that fibroblasts play a prominent role in this resistance [10] In that study, Spalax fibroblasts were able to inhibit growth and kill adjacent cancer cells of humans and other mammals via direct cell-to-cell interaction in co-culture models, or via fibroblast-generated conditioned medium when transferred to cancer cells growing alone. This scenario was accompanied by decreased cancer cell viability, disturbed cell cycle progression, nuclei deformation, and mitochondrial fragmentation.

In the current investigation, we have attempted to elucidate some of Spalax's molecular mechanisms that enable cancer resistance at the gene-regulation level. We compared the response of Spalax and mice to a single subcutaneous injection of the chemical carcinogen 3-methylcholanthrene (3MCA) to the left flank of the neck. All 12 injected mice developed the expected fibrosarcoma tumor 10 to 14 weeks following the injection. Out of the 22 injected Spalax individuals, however, two animals developed a benign granuloma after 14 and 16 months, and only two developed the expected fibrosarcoma 18 months [10] and 30 months (reported here) after the injection.

By comparing the transcriptome of Spalax's and mice's injected versus uninjected tissues and untreated samples, we unraveled differences in the regulation of some of the major genes and pathways that seem to contribute to Spalax's significantly high cancer resistance. We found a higher elevation of anti-cancer pathways in Spalax and that many of the differentially regulated genes belong to three major groups: the innate immune system, the extracellular matrix (ECM), and DNA repair machinery. We have concluded that the stronger activity of the Spalax's innate immune system and the elevated expression of tumor suppressor genes related to the ECM compared to those in mice, may play an important role in Spalax tumor surveillance. These regulations, together with the Spalax's basic higher levels of expression of genes that belong to DNA damage repair pathways and DNA metabolism, may enable Spalax's higher tolerance to carcinogens (in particular 3MCA) and to its generally extraordinary cancer resistance.

\section{Results}

Spalax and mice were treated with the carcinogen 3MCA; muscle tissue samples were then collected from the injection site, the developed tumor, the opposite (uninjected) side, or the untreated control (Details shown in Table 1). Since we had samples from various conditions, we tried to organize the investigation in the following fashion. To uncover a possible genetic predisposition to cancer resistance and cancer influence on the surrounding tissue, we compared tissue from untreated Spalax to tissue taken from the uninjected side of the neck of Spalax with tumor growth. We extended this comparison to tissue from mice (which we consider tumor susceptible) to identify genes related to universal cancer development (Fig. 1).

In an attempt to uncover cancer-resistance mechanisms and to further understand what makes Spalax generally different in its non-susceptibility to cancer induction, we compared samples from tumor-resistant Spalax with samples retrieved from four Spalax individuals that failed to resist chemical carcinogenesis to different degrees.

\section{Identification of genes expressed in carcinogen-tolerant Spalax}

We took samples from various conditions in Spalax and mice (Table 1). Four samples of untreated Spalax 
Table 1 List of animals used in this study

\begin{tabular}{|c|c|c|c|c|c|c|c|c|}
\hline \multirow[t]{2}{*}{ Species } & \multirow[t]{2}{*}{ ID } & \multirow[t]{2}{*}{ Name } & \multirow[t]{2}{*}{ Sex } & \multirow[t]{2}{*}{ Treated } & \multirow[t]{2}{*}{ Diagnosis } & \multicolumn{2}{|c|}{ \# Samples } & \multirow{2}{*}{$\begin{array}{l}\text { Time of } \\
\text { operation }\end{array}$} \\
\hline & & & & & & $\overline{U I S}$ & IS & \\
\hline Spalax & 1042 & Spalax control & $\mathrm{F}$ & - & healthy & $1 x$ & - & - \\
\hline Spalax & 1075 & Spalax control & $\mathrm{F}$ & - & healthy & $1 x$ & - & - \\
\hline Spalax & 2095 & Spalax control & $\mathrm{F}$ & - & healthy & $1 x$ & - & - \\
\hline Spalax & 6038 & Spalax control & $\mathrm{F}$ & - & healthy & $1 x$ & - & - \\
\hline Spalax & 2251 & Spalax tolerant & M & $3 \mathrm{MCA}$ & healthy & - & $1 x$ & 18 months \\
\hline Spalax & 2261 & Spalax tolerant & M & $3 \mathrm{MCA}$ & healthy & - & $1 x$ & 18 months \\
\hline Spalax & 2218 & Spalax tolerant & M & $3 \mathrm{MCA}$ & healthy & - & $1 x$ & 30 months \\
\hline Spalax & 2375 & Spalax tolerant & $\mathrm{F}$ & $3 \mathrm{MCA}$ & healthy & - & $1 x$ & 30 months \\
\hline Spalax & 600 & Spalax granuloma & $\mathrm{F}$ & $3 \mathrm{MCA}$ & granuloma & $1 x$ & $1 x$ & 14 months \\
\hline Spalax & 976 & Spalax granuloma & $\mathrm{F}$ & $3 \mathrm{MCA}$ & granuloma & $1 x$ & $1 x$ & 16 months \\
\hline Spalax & 2240 & Spalax fibrosarcoma & $\mathrm{F}$ & $3 \mathrm{MCA}$ & fibrosarcoma & $1 x$ & $1 x$ & 18 months \\
\hline Spalax & 2230 & Spalax fibrosarcoma & M & $3 \mathrm{MCA}$ & fibrosarcoma & $1 x$ & $1 x$ & 30 months \\
\hline mice & M1 & mice control & M & - & healthy & $1 x$ & - & - \\
\hline mice & M2 & mice control & M & - & healthy & $1 x$ & - & - \\
\hline mice & M5 & mice control & M & - & healthy & $1 x$ & - & - \\
\hline mice & 1019 & mice & M & $3 \mathrm{MCA}$ & fibrosarcoma & $1 x$ & $1 x$ & 14 weeks \\
\hline mice & 1023 & mice & M & $3 \mathrm{MCA}$ & fibrosarcoma & $1 x$ & $1 x$ & 12 weeks \\
\hline mice & 512 & mice & M & $3 M C A$ & fibrosarcoma & $1 x$ & $1 x$ & 11 weeks \\
\hline
\end{tabular}

Outlining the animals used in this study. The number of samples is separated into the uninjected side and injected side. The time of operation is the time after treatment with $3 \mathrm{MCA}$

animals as the control group were used, as well as four samples from animals that were injected but did not develop tumors after 18 and 30 months, which we term "Spalax tolerant." Out of 22 treated Spalax, four developed a tumor: two a malignant fibrosarcoma and two a benign granuloma. The granuloma samples were pathologically defined as spindle cell proliferation reflecting fibrosis at the site of an incompletely resolved inflammation, whereas fibrosarcomas were described as highly mitotic and heavily inflamed spindle and epithelioid cell tumors [10]. From these animals, samples were taken from the injected side, or

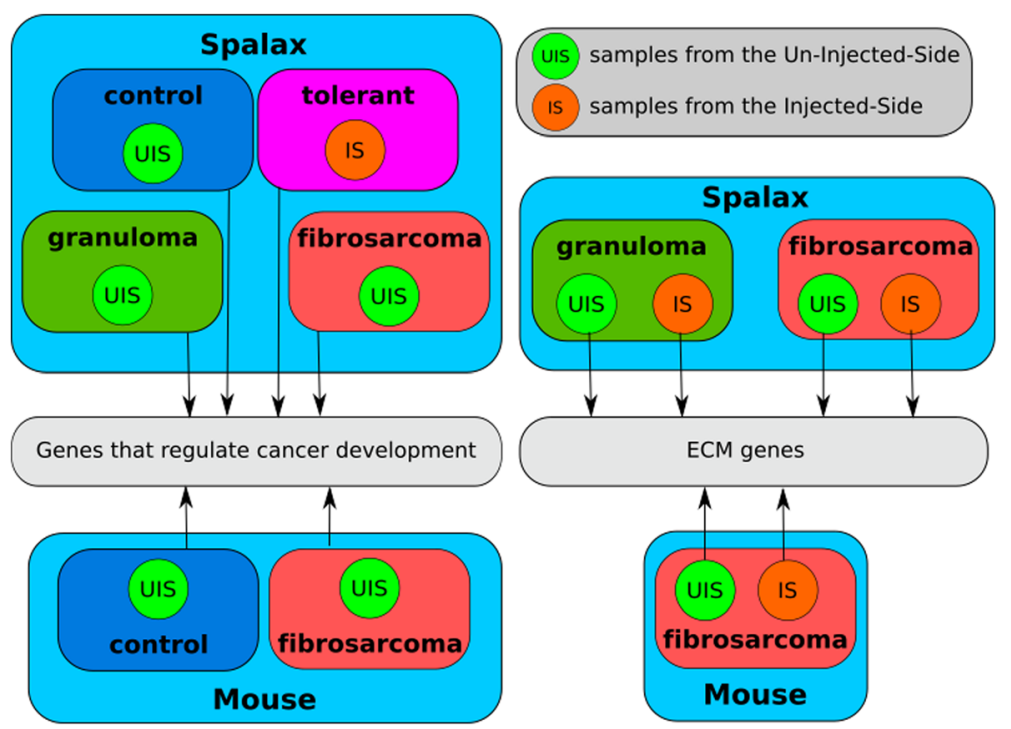

Fig. 1 Data sets used in the specific experiments. Diagram depicting the data usage of the experiments 
IS (i.e., from the tumor), and from the uninjected side (UIS) of the neck. All treated mice developed a tumor. Samples were also taken from three mice on the IS with the tumor and the UIS. In addition, samples from three untreated control mice were used as control.

After filtering, trimming, and mapping these RNA-Seq samples, we investigated the effects of the 3MCA treatment and the relation between these samples. We then clustered the expression values (Fig. 2). The analysis showed a separation of the samples by phenotype first, and then by species. The samples of Spalax untreated control and "Spalax tolerant" were direct neighbors. Close to this subgroup were the UIS samples of Spalax with fibrosarcoma and then granuloma. Mice control and mice UIS samples were also paired together but were still closer to the non-carcinogenic tissues of Spalax than to the carcinogenic tissue samples. All samples taken from tumor tissue were clustered in the same branch, first pairing samples from Spalax and then mice.

Because the development of tumors has an extensive impact on gene expression, it is generally difficult to distinguish between expression changes that allow tumor growth from those that are subsequently induced by the tumor. To assess how cancer development in Spalax affects genome expression in the neighboring tissues, we compared the Spalax control with the Spalax UIS from the animals with tumors by pooling them together. We discovered 68 annotated genes to be differentially expressed (Additional file 1: Table S2). To determine which of these 68 genes could be considered as plausible candidates for cancer susceptibility, we added mice

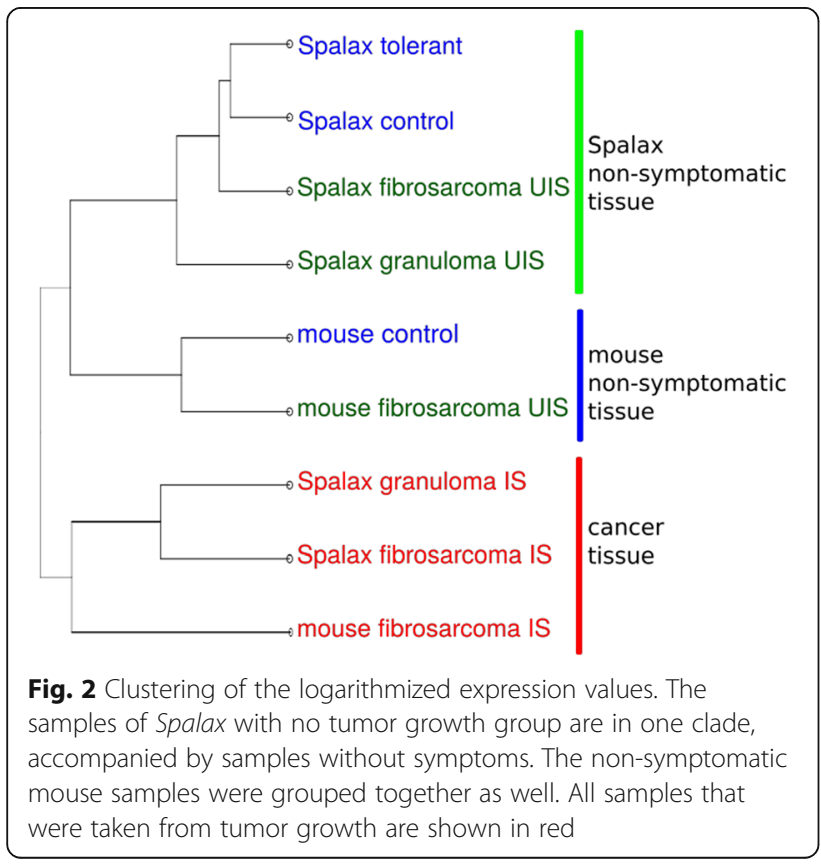

samples to the analysis. Mice have a very low cancer resistance, so we were interested in the expression behavior of these genes in mice samples. We clustered the 68 genes according to their expression patterns and included all data sets at our disposal, excluding tumor tissue, namely Spalax UIS (of granuloma and fibrosarcoma bearing animals), mice control, and mice UIS (fibrosarcoma bearing). In this part of the study we omitted the tumor tissue to avoid introducing the large variances found in tumors.

In this clustering, we found 25 genes with distinct expression patterns (Fig. 3). Twelve of these genes displayed a general up-regulation in the susceptible samples compared to the Spalax control. These genes contain known cancer-related genes such as Jak3, Foxol, and Cdkn1a (p21). The remaining 13 genes showed a general down-regulation in the susceptible tissue samples, i.e., of mice and tumor-bearing Spalax. We found known cancer-related genes such as Ntrk1, Serpina6, Nme3, and Sstr4. We also found significant differences in the level of expression of mitochondrial uncoupling protein (UCP1) in tumor-resistant samples (Spalax control and Spalax UIS cancer negative) in comparison with the cancer-sensitive group (mouse control, mouse UIS, and Spalax UIS cancer positive). The low level of UCP1 expression in the tolerant samples may have reflected a high level of natural defenses against cancer via mitochondrial homeostasis. Nucleoside diphosphate alkylase 2 (NME2), which is an active cancer suppressor, was highly expressed in Spalax tissues (Fig. 3).

We then conducted microRNA analysis in Spalax and mice tumor-bearing individuals. microRNAs are small $(\sim$ 22 nucleotides) non-coding RNA molecules. They act as post-transcriptional modifiers that can silence a gene. We found nine microRNAs that were connected to the candidate genes, either as microRNA regulators or as potential targets. Differential expression analysis was performed for the comparison of UIS vs. IS in granulomas and fibrosarcomas in Spalax as well as for fibrosarcomas in mice (Additional file 1: Table S3). We found 27 microRNAs that targeted Cdkn1a and Foxo1. Since microRNAs act as suppressors of gene expression, we expected the microRNAs and the target genes to have opposing expression patterns in the three comparisons between the UIS and IS in Spalax granuloma, Spalax fibrosarcoma, and mice fibrosarcoma. Three microRNAs that target Foxo1 showed this pattern (miR-182, miR-223, and miR-96), and one for Cdkn1a (miR-296), as shown in Fig. 4. Although which genes regulate these microRNAs remain unknown to date, we hypothesize this pattern as a partial explanation for the regulation we observed.

Investigation of Spalax individuals that developed cancer Since cancer development is a relatively rare event in Spalax, we were especially interested in investigating the 


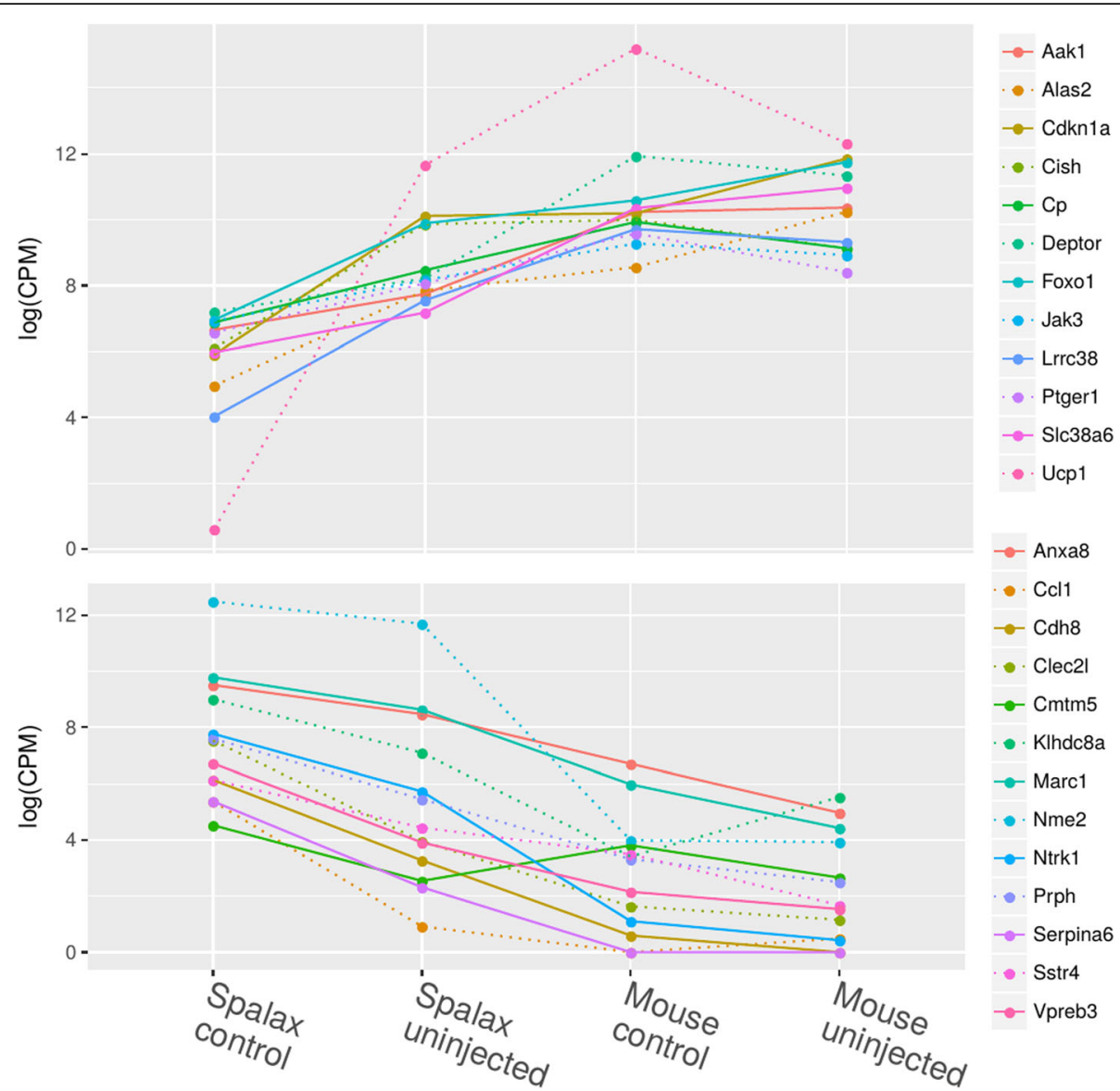

Fig. 3 Genes that show the same pattern in Spalax control vs. all other samples. The Spalax uninjected pools sample includes both Spalax with fibrosarcoma and granuloma. While Spalax tolerant resisted the 3MCA injection, Spalax uninjected, mouse control, and mouse uninjected are considered "susceptible" to tumor growth. The upper diagram shows genes that are generally up-regulated in all susceptible samples; the lower diagram shows genes that are generally down-regulated

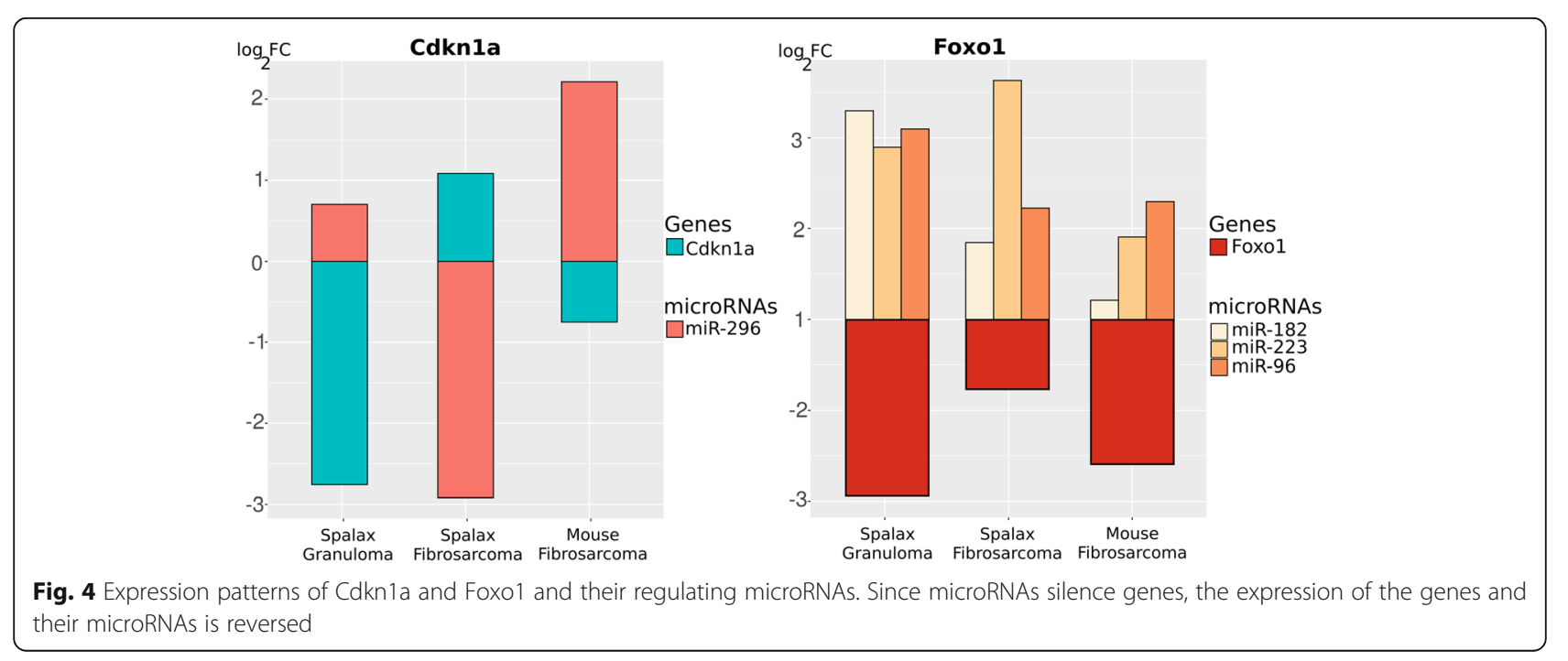


four animals that did develop tumors, specifically the transcriptome differences between those that managed to limit the growth to a benign granuloma and those that formed a malignant fibrosarcoma, similarly to mice. To explore the differences between the two groups, we compared the uninjected side of the treated Spalax with the injected, tumor side of the animals using gene expression analysis. In the comparison of the samples of granuloma tissues, we found 2316 differentially expressed genes (DEGs). The fibrosarcoma samples showed 3293 DEGs. The intersection of these two gene sets consisted of 1736 genes. We split the functional analysis into three parts:

1) genes that were differentially expressed in both tumor types (Additional file 1: Table S7);

2) genes that were differentially expressed only in animals with granulomas (Additional file 1: Table S8); and

3) genes that were differentially expressed only in animals with fibrosarcomas (Additional file 1: Table S9).

Functional analysis of the DEGs showed that in all three comparisons, the dominant categories were the extracellular matrix, the citrate cycle, the cell cycle, and the immune system. These categories are all typically influenced by cancer development. We also directly compared the tissue from the uninjected sides of Spalax with fibrosarcoma and Spalax with granuloma (section 3.3). We found only 84 DEGs, indicating that despite the different tumors, the tissues were very similar. Once again, ECM-related categories dominated the enrichment analysis.

Since several of the tests showed an enrichment of genes belonging to the extracellular matrix and the immune system, we focused our investigation accordingly.

We focused on genes that were related to the extracellular matrix and collagen formation, as they were found to be significantly differentially expressed in both fibrosarcoma and granuloma tumors. This analysis showed that genes were generally up-regulated in the ECM categories (Additional file 1: Table S1). This finding is not surprising, since the modification of the extracellular matrix is a hallmark of cancer that allows growth and invasion into neighboring tissue and stimulates blood vessel growth. We continued to investigate the ECM-related genes on their connectivity, stability in expression (i.e., low variance between the samples of the same condition), and the known effects on tumor growth. We found a highly connected network of seven genes, namely Aspn, Chad, Fbln, Kera, Lum, Omd, and Sfrp1. (See Table 2 for a description of these genes.) The genes are connected via shared protein domains and
Table 2 Short description of the ECM genes that form a regulatory network

Aspn (Asporin) is an extracellular matrix protein that modulates the Transforming Growth Factor $\beta$ (TGF $\beta$ ) signaling pathway, regulating cartilage matrix gene expression and cartilage formation [60]. Aspn inhibits TGF $\beta 1$, a biomarker of poor prognosis in cancer [61]. High asporin expression is significantly associated with less aggressive tumors, which could explain the benign growth.

Chad (Chondroadherin) expression has been linked to significant decreases in hepatocellular carcinoma, both in mRNA and protein levels. Chad abundance correlates with differentiation and metastasis, while the reduction of Chad levels significantly enhances proliferation and migration [39]. Chad has a a2 $\beta 1$ integrin binding sequence that previous studies have found counter cancer development [62].

Fbln5 (Fibulin-5) is frequently silenced in lung cancer and suppresses cell invasion by inhibiting the Wnt/B-catenin pathway [63]. Fbln5 has also been shown to reduce reactive oxygen species (ROS) production by modulating cell-ECM interactions [64]. Excessive ROS production results in cellular toxicity, which can promote tumor growth.

Lum (Lumican) has different effects on cancer development, depending on the type of tumor and whether Lum is expressed in the cell or in the adjacent stromal tissue [65]. Lum also acts as an oncogene, but if present in the surrounding stroma, it can restrict cancer progression and migration.

Sfrp1 (Secreted frizzled-related protein 1) is an antagonist of Wnt signaling, which gives Sfrp1 its tumor-suppressive effect. The loss of Sfrp 1 has been hypothesized to activate MAPK or the non-canonical Wnt pathway [66]. One mechanism of how this loss can occur is the methylation of Lum via HP1a.

Kera (Keratocan) encodes a protein that is involved in corneal transparency. Mutations can cause cornea plana [67].

Omd (Osteomodulin) is an extracellular matrix keratan sulfate proteoglycan that is also connected to bone development [68].

Igf2 (Insulin-like growth factor 2) is a mitogenic peptide hormone expressed by liver and many other tissues. It is closely associated with cancer $[69,70]$.

Cebpa (Transcription factor CCAAT / enhancer-binding protein alpha) is an important protein during embryogenesis, glucose metabolism, adipogenesis, and myeloid development $[16,30,71]$.

Jun Jun is part of the transcription factor activator protein 1 and has been closely associated with cancer development $[15,72,73]$.

co-expression, which were found using GeneMANIA annotation software [11] and various publications [12-14].

Figure 5 shows the connected genes, where Lum and Aspn are highly connected hub genes. Since it is difficult to determine the regulatory direction of co-expression, and a shared protein domain is by its nature undirected, it is also difficult to distinguish between regulators and targets. Our analysis showed that this gene complex was generally up-regulated in Spalax granulomas and mice fibrosarcomas (compared to uninjected tissue) while being down-regulated in Spalax fibrosarcomas.

In addition to the cellular matrix genes, we also found connections to the cell growth genes Igf2, Jun, and 


\section{uninjected side vs Fibrosarcoma}

\section{uninjected side vs Granuloma}
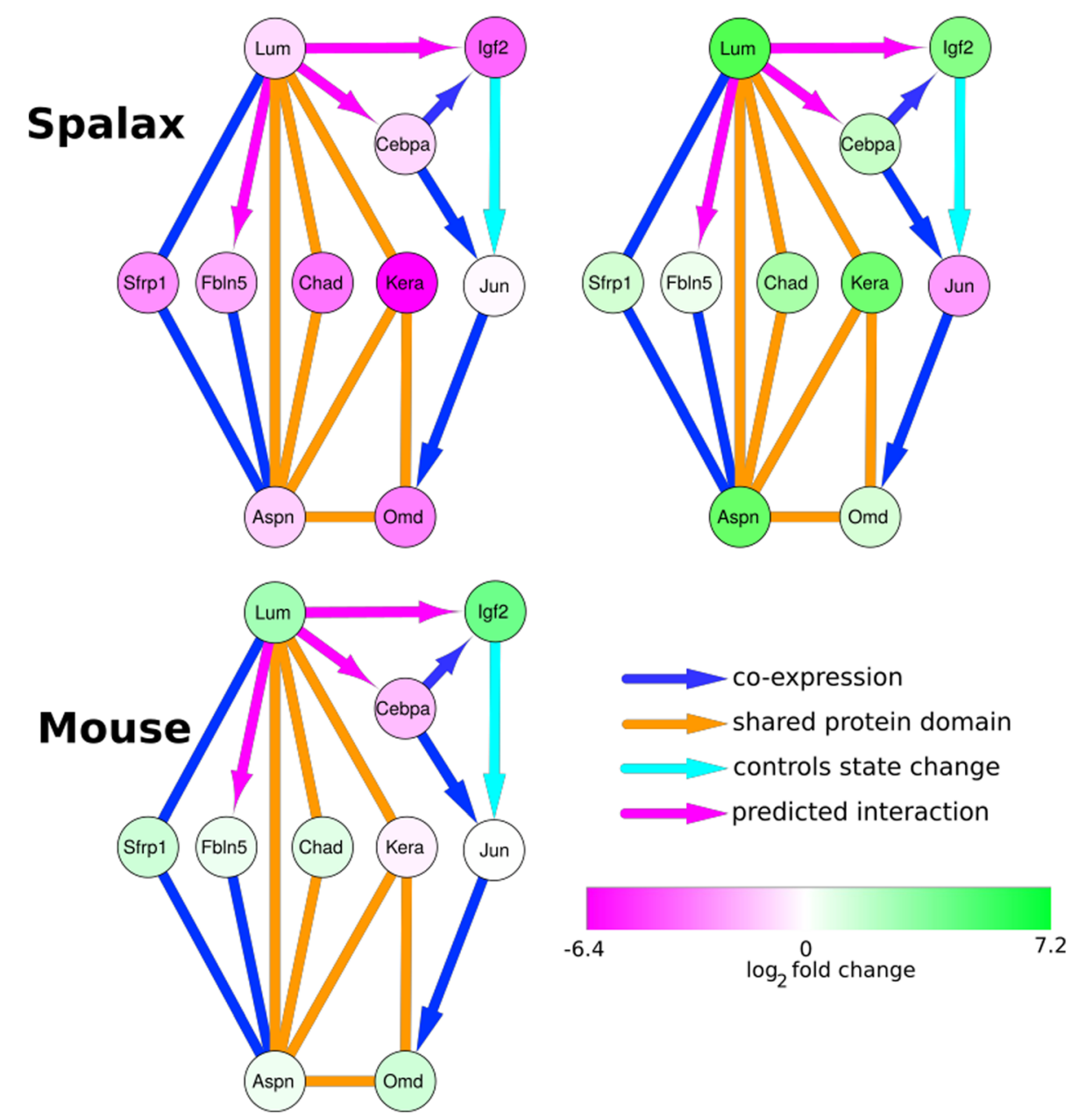

Fig. 5 Regulatory center genes in different animals and conditions. The color of the nodes represents the log2 fold change in the comparisons of the uninjected with the injected tissue

Cebpa. While they are not directly involved in matrix generation, they are connected to the central ECM gene Lum. Jun is part of the hetero-dimer AP-1, and centrally involved in prostate cell migration and invasion. Furthermore, $A P-1$ was reported having a significant role in melanomas [15]. Cebpa is down-regulated in gastric cancer, and potentially useful for its treatment [16]. Nevertheless, Igf2 and Cebpa were clearly regulated differently in Spalax fibrosarcoma samples than in the granuloma samples.

In mice, the picture was more ambiguous. While the genes related to cellular matrix complex are generally up-regulated, the intensity of the up-regulation is much smaller, and often not statistically significant.

While not presented in this network, other important ECM-related genes were also found to be differentially regulated in Spalax and mice. The gene Creb3l1 was found to be more highly expressed in Spalax granulomas compared to the fibrosarcomas of both mice and Spalax. In addition, Emilin2 is up-regulated and inhibits the Wnt-signaling pathway [17]. Other genes were also found to be up-regulated, including $B m p 7$, which antagonizes transforming growth factor $\beta 1$ (TGF $\beta 1$ )-mediated fibrosis through suppressing epithelial-mesenchymal transition [18], and $M m p 8$, which prevents metastasis formation through the modulation of tumor cell adhesion and invasion [19].

We then performed microRNA analysis of the ECM genes. We used the microRNA data to explain the impact of the genes involved. We found nine microRNAs that were connected to the ECM genes, either as micoRNA regulators or as potential targets. Differential expression 
analysis was carried out for the comparison of UIS vs. IS in granulomas and fibrosarcomas in Spalax, and in fibrosarcomas in mice (Additional file 1: Table S4). Four of these nine microRNAs were found to be regulated by Cebpa, yet none matched the expression pattern of Cebpa as a gene. We believe that an additional regulatory mechanism must be responsible for this expression pattern. We must point out, that the knowledge about microRNAs and genes were taken from mice annotation. This has to be taken into consideration when evaluating the impact of these findings.

In this part of the study, we compared the two different tumor tissues (granuloma and fibrosarcoma) to uninjected tissue. We identified a tight network of genes from the extracellular matrix, which then allowed us to hypothesize that the modulation of ECM in Spalax granuloma largely contributes to host resistance.

\section{Direct comparison of uninjected tissue of Spalax with tumor}

In general, the transformation from normal cell to cancer cell is accompanied by an extensive altering of gene expression. In the current experimental setup, it was difficult to determine which changes in the observed major shift in gene expression were the drivers of cancer development and which changes were secondary to tumorigenesis. This situation is especially important in order to understand the difference between Spalax and mice. We started by comparing the uninjected side (UIS) with the injected side (IS) in Spalax to determine the extent of genetic rewiring. We considered a $|\log 2 \mathrm{FC}| \geq 2$ as a threshold for highly differentially expressed genes (see Additional file 1: Table S6). Among all DEGs in the described experiments, we filtered the genes that belong to these categories: cell cycle, citrate cycle, immune system, extracellular matrix, hypoxia response, and degenerative diseases (Table 3). The ECM has the most differentially expressed genes of these categories, followed by cell cycle.
To investigate the differences between the species, we included the mice tumor samples in our analysis. We looked at genes that showed an expression difference between the species of $|\log 2 \mathrm{fc}| \geq 1$. The highest differences were found in hypoxia-related genes (88/ 164 genes, $54 \%$ of the group members). The second group was related to the cell cycle control $(84 / 239$, $35 \%$ of the group members), the third was the immune system group (43/125 genes, $34 \%)$, and the fourth was the ECM group (57/269, 21\%).

In the analysis, Spalax showed a larger number of up-regulated tumor suppressors (39:21) and more down-regulated tumor promoters compared to mice (36:27). Most of the anti-cancer reprogramming of gene expression in Spalax seems to occur in the three gene groups of immune system 17/43 (40\%), ECM 21/57 (37\%), and hypoxia responsive 22/88 (25\%).

The elevation of Tlr4, Ifngr1, Ifnar2, Stat1, and Irf1 is presumably a part of an integrated pathway. The levels of Stat1 in Spalax in response to 3MCA injection were found to be five times higher compared to mice. These elevated Stat1 levels seemed to contribute to the tumor surveillance Interferons-I, which were found to systemically activate natural killer cell activity.

We also found stronger down-regulation of $m T O R$ mRNA expression in Spalax compared to mice. In this regard, the elevation of the hypoxia-responsive Ddit4 in Spalax, compared to its down-regulation in mice, should also be noted, as up-regulation of Ddit4 expression mediates $m T O R$ inhibition and growth inhibition in cancer cells [20].

By comparing the control, untreated Spalax, and mice groups, we found higher basic levels of expression of $75 \%$ of the 54 genes that belong to the Fanconi Anemia pathway. Fanconi Anemia genes are involved in the homologous recombinational repair of DNA double-strand damage, inter-strand crosslinks repair, and mismatch repair. The ratios between the control groups of the mRNA

Table 3 Analysis of the highly differentially expressed genes following 3MCA injection

\begin{tabular}{|c|c|c|c|c|c|c|c|}
\hline & Immune & ECM & Hypoxia & Cell cycle & Citrate cycle & Degenerative diseases & \# of genes \\
\hline $\mathrm{HDEG}^{\mathrm{a}}$ & 125 & 269 & 164 & 239 & 74 & 159 & 888 \\
\hline$D E^{b}$ & 43 & 57 & 88 & 84 & 9 & 21 & 220 \\
\hline $\mathrm{TSU}^{c} \mathrm{~S}>\mathrm{M}^{d}$ & 13 & 14 & 8 & 6 & 1 & 5 & 39 \\
\hline TSU $M>S^{d}$ & 4 & 4 & 3 & 5 & - & 5 & 21 \\
\hline $\mathrm{TPD}^{\mathrm{e}} \mathrm{S}<\mathrm{M}^{\mathrm{f}}$ & 4 & 7 & 14 & 9 & - & 4 & 36 \\
\hline TPD $M<\mathrm{S}^{f}$ & 4 & 9 & 6 & 6 & - & 5 & 27 \\
\hline
\end{tabular}

${ }^{\mathrm{a}} H D E G$ highly differentially expressed genes $|\log 2 f| \geq 2$

${ }^{\mathrm{b}} D E$ Differentially Expressed-the number of HDEG refers to when the difference in the change between the species following the 3-MCA injection is $\mid$ log2f $\mid \geq 1$ ${ }^{\mathrm{C}}$ TSU Tumor Suppressors Up-regulated

${ }^{d} S>M, M>S$ : higher elevation in the Spalax compared to the mice, or the mice compared to the Spalax, respectively eTPD Tumor Promoters Down-regulated

${ }_{\mathrm{f}}^{\mathrm{S}}<\mathrm{M}, \mathrm{M}<\mathrm{S}$ : stronger down-regulation in the Spalax compared to the mice, or the mice compared to Spalax, respectively 
expression (Spalax/mice) were found to be high for most of the genes (Table 4 and Fig. 6).

\section{Discussion}

The treatment with 3MCA resulted in the development of fibrosarcoma in 12 out of 12 mice within 3 months, while only 4 out of 22 Spalax developed tumors during this time; two of them developed a benign granuloma by 14 and 16 months, and two had developed the expected fibrosarcoma by 18 and 30 months following the carcinogenic treatment. For malignant tumors only, Fisher's exact testing showed significant differences ( $p$-values of $3.32 \times 10^{-6}$ and $1.66 \times 10^{-7}$ for all tumor outcomes).

We showed in this study that Spalax is highly resistant to the carcinogenic effects of 3MCA injection. While the investigation of "confirmed" cancer resistance is important for the understanding of cancer mechanisms, the investigation of failed cancer resistance is no less valuable. Of special interest in this study is the fact that four Spalax failed to escape tumor growth in different ways, where two of them managed to "contain" the process, which ended in the formation of benign tumors. Although two cases of each type were the smallest sample size for statistics purposes, this examination provided an opportunity to gain deep insights into the carcinogenesis of these subterranean mammals.

The first investigation of the samples via clustering showed that the most significant division between the samples was between tumor tissue and non-treated

Table 4 List of Fanconi anemia genes

\begin{tabular}{ll}
\hline Gene & up regulation \\
\hline Atrip & $60 x$ \\
Brca1 & $3 x$ \\
Brca2 & $10 x$ \\
Cenps & $3 x$ \\
Eme1 & $\times 336$ \\
Fanca & $10 x$ \\
Fancc & $10 x$ \\
Fanci & $55 x$ \\
Fancn & $55 x$ \\
Fen1 & $178 x$ \\
Pms2 & $5 x$ \\
Rad51c & $11 x$ \\
Rmi2 & $6 x$ \\
Top3 & $5 x$ \\
Wrn & $3 x$ \\
Telo2 & $5 x$ \\
\hline
\end{tabular}

List of Fanconi anemia genes that are up-regulated between Spalax control and mice control tissue, with the genus as the second divider (Fig. 2). Since tumors are generally considered to be organs developing in the context of organisms [21], tumor growth has a larger impact on the overall expression than the species factor. The Spalax tolerant samples clustered together with the Spalax control, which shows that the Spalax that did not develop a tumor were indeed affected very little by the treatment. The UISs of the fibrosarcoma and granuloma individuals were positioned on neighboring branches of the graph, showing that the tumor did seem to have a major impact on genome expression in the cells of neighboring tissue. Interestingly, the UISs of the fibrosarcoma tissue was closer to the Spalax control/tolerant than the UISs of the granuloma tissue, which was also visible during other parts of the investigation. We hypothesize that Spalax with benign tumors mounted substantial defense mechanisms, which were reflected in the extensive changes in gene expression in the neighboring tissue.

We found that the mice control and mice UIS of fibrosarcoma had their own branches and were still closer to the untreated samples of Spalax than to the clade with all the tumor tissues, which implies that extensive rewiring in the gene expression caused by the tumor growth occurred. We found 25 genes that behaved consistently different in animals that developed any type of tumor regardless of the species (Fig. 3). While some of these genes have been described in the literature as being related to cancer, our work can extend that knowledge by showing how these genes react in different species and conditions. Some of these genes are known cancer-promoting or suppressing genes such as Cdkn1a and Foxo1. While the precise mechanisms are unknown, and extensive investigations will be required to validate these findings, we propose these genes/gene networks as candidate genes that contribute to cancer resistance in Spalax.

Since the population of Spalax is not homogeneous, like any population of non-inbred wild animals, it is natural to assume that among the heterogeneous group will be those that cannot avoid the carcinogenic stimulus. On the contrary, the cancer-prone population of the laboratory mice demonstrated rapid response to carcinogen treatment by the development of fibrosarcoma. Thus, tissues for analysis from untreated and UIS treated mice were considered to be samples with very low threshold levels. To determine whether individual tumor sensitivity in Spalax is genetically pre-determined, we organized the samples for comparative analysis as follows [1]: cancer sensitive (mouse untreated and UIS of tumor-bearing mice as well as UIS of Spalax, in which we observed the neoplastic processes) and [2] cancer resistant (Spalax control plus Spalax tumor-negative UIS). See Fig. 3. 
FANCONI ANEMIA PATHWAY

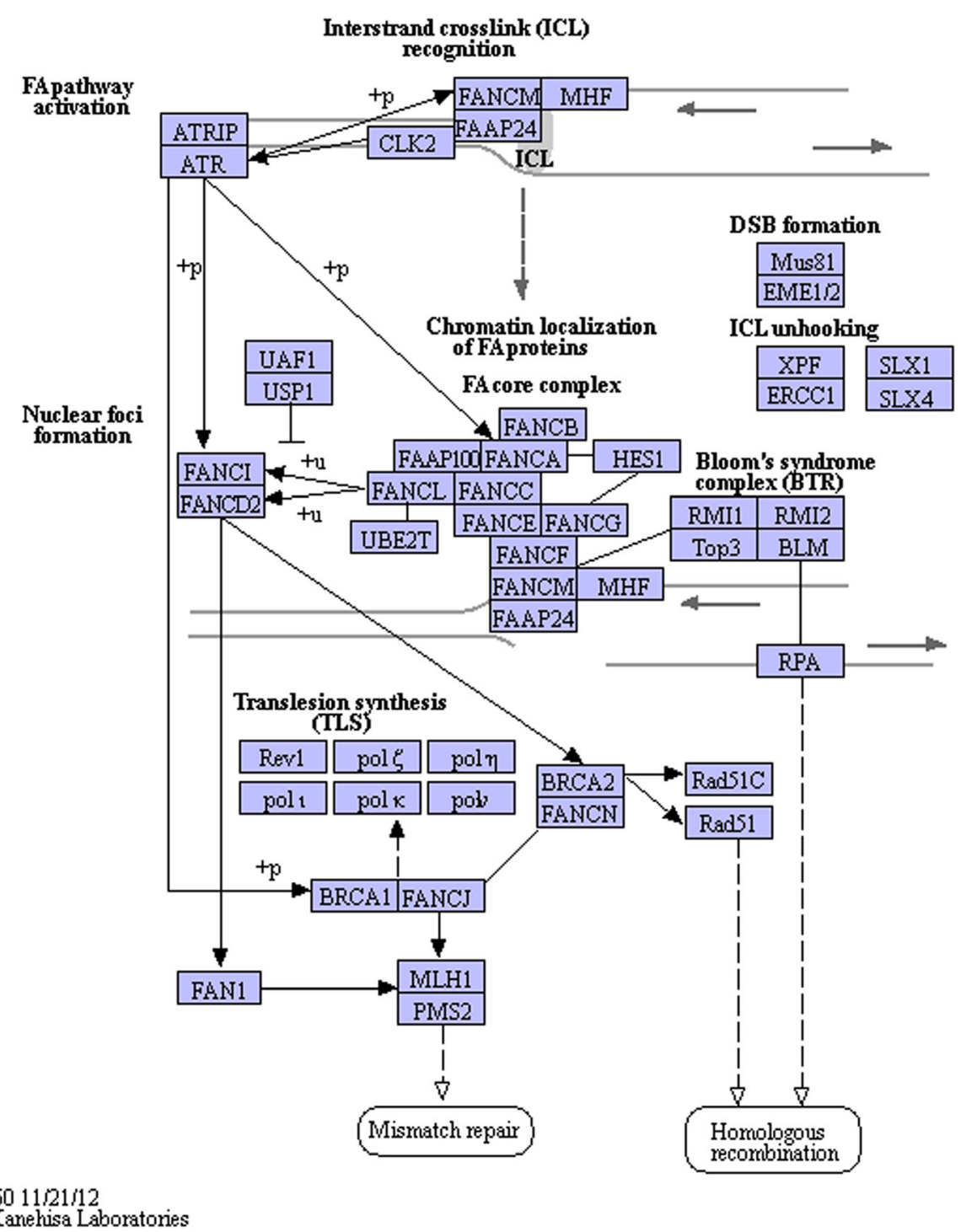

Fig. 6 The Fanconi Anemia pathway

During tumor progression, already mutated cells constantly co-interact with stromal host cells, which can either promote or suppress the growth of malignant cells [22]. In this context, the outcome depends to a large extent on the abilities of the stromal host cells to maintain homeostasis, integrity, and oxidative metabolism. According to the paradigm of tumor cell metabolic parasitism, host cells "fuel" the anabolic growth of cancer cells through energy transfer [23].

The role of the mitochondrial metabolism in the development of cancer is of great interest. Mitochondrial uncoupling protein 1, or UCP 1 (also known as thermogenin), was originally associated with the brown adipose tissue of mammals. UCP1 promotes proton leakage from the inner mitochondrial membrane independent of ADP phosphorylation; this leakage uncouples respiration from ATP synthesis, thus dispersing the energy of oxidation in the form of heat $[24,25]$. Previous studies have demonstrated the unique changes in the $U C P 1$ sequences of the naked mole rat and have discussed these sequences' possible roles in these mammals' thermoregulation and longevity [26]. UCPs are currently being investigated for their potential role in cancer initiation and development [27]. In studying the role of UCP1-overexpressing cancer-associated fibroblasts (hTERT-BJ1) in human breast cancer cell (MDA-MB-231) growth, a previous 
study has demonstrated increased $\beta$-oxidation, ketone body production, and the release of ATP-rich vesicles, all of which "fuel" tumor growth [23]. Conversely, the induction of mitochondrial dysfunction via UCP transfection of MDA-MB-231 cells results in significant reductions in tumor growth. Thus, if a rapidly growing tumor does not receive "fuel" from surrounding tissues, then the tumor may undergo involution by "eating itself." The comparative analysis of cancer-sensitive and cancer-resistant samples in our study revealed a dramatic difference in the levels of $U C P 1$ gene expression (Fig. 3). We can assume that a high level of expression of $U C P$ in tissues may represent a predictive marker for carcinogenesis susceptibility.

Another prognostic marker of cancer development, nucleoside diphosphate alkylase 2 (NME2), was differentially expressed in our study's mouse samples (low expression level) and in Spalax samples (high expression level), including samples derived from the UIS of cancer-sensitive Spalax (Fig. 3). NME2 have been extensively studied in the past for their cancer-suppressing activities [28]. Previous studies have shown that an overexpression of NME2 reduces the migration and invasion of gastric cancer cells to the cellular matrix in vivo and in vitro. Subsequently, NME2 expression is associated with the well-differentiated and less invasive histology of gastric cancer. The high level of expression of NME2 gene in the Spalax-sensitive samples found in our study may explain to a certain extent the significant delay of tumor development and the tumors' benign nature in half the cases. In addition, Somatostatin Receptor 4. (SSTR4), which we found to be more highly expressed in Spalax tissues (Fig. 3), could inhibit the proliferation of normal cells or tumor cells and suppress the formation of tumor vessels via releasing hormone-inhibiting tumor growth [29].

Even though four Spalax animals failed to resist the treatment with 3MCA in our study, this failure occurred in two distinct ways. We explored the differences between the benign granuloma and the malignant fibrosarcoma. One of our main findings was a cluster of key regulators in the extracellular matrix pathway. The ECM gene cluster including the Lum, Sfrp1, Fbln5, Chad, Kera, Aspn, and Omd genes was found to be distinctly more activated in granulomas than in fibrosarcomas. Especially noteworthy is that the activation of highly connected tumor suppressors and anti-metastatic genes such as Lum and Aspn may have explained the stunted growth of the tumor. The cell growth genes Igf2 and Cebpa are also up-regulated in granuloma. These genes are generally up-regulated in cancer cells, although Cebpa has also been reported to act as a tumor suppressor [30]. It was interesting to note that these cancer genes were activated in the benign tumor in our study, while the malignant growth seemed to have deactivated these genes..

The extracellular matrix plays a significant role in cancer, with both tumor promoting and inhibiting effects [31]. The switch in the citrate cycle is likely related to the Warburg effect, where the tumor switches from aerobic to anaerobic glycolysis. This switch enables the tumor to use the available glucose for other processes, such as cell division [32]. Removing cell cycle checkpoints is a basic requirement for the uninhibited proliferation of tumor cells, while cell cycle arrest is a common mechanism involved in tumor suppression [33]. Regulating the genes of the immune system is a crucial factor to prevent the organism from attacking the tumor [34].

Creb3l1 is an endoplasmic reticulum gene that is a transcription factor and a metastasis suppressor. It has been found to repress the expression of the genes that regulate metastasis, invasion, and angiogenesis in both breast cancer and bladder cancer [35]. We found in our study that the expression of Creb3l1 was higher in the granulomas of Spalax compared to the fibrosarcomas and may have been an important factor in preventing the development of malignant fibrosarcoma.

We attempted to elucidate the connections between these ECM genes in our study. As shown in Figs 5, 13 interactions were found to belong to the class of shared protein domain or co-expression. Because the nature of these interactions makes it impossible to infer a direction of the regulation, it is difficult to determine which gene induced a reaction and which genes were influenced. We did find a few differentially expressed microRNAs, mainly regulated by Cebpa. The expression patterns of the microRNAs and Cebpa did not match, however, thus indicating the presence of complex regulation activities and additional interactions that we are not aware of. Another explanation is, that there are species specific microRNAs, that are not present in mice.

The hypoxic environment Spalax lives in causes DNA damage through the occurrence of reactive oxygen species production. Spalax has adapted to this over the years by developing a very efficient DNA repair mechanism [36] that subsequently prevents persistent DNA damage and ultimately prevents cancer development by repairing harmful mutations. 3MCA is a DNA-damaging agent, and Spalax reacts to this damage by activating DNA-repair genes, especially the Fanconi anemia genes. In our study, most of the Fanconi anemia genes already had a higher expression in the untreated control groups. Similar results have been shown in a previous comparison between the transcriptome of the brain and liver [5, 7] (Additional file 1: Table S5).

In addition to its enhancement of the DNA-repair effect, the hypoxic habitat of Spalax also appears to make 
the expression of hypoxia-related genes more attuned to countering cancer development. We found that more tumor suppressors up-regulated and more tumor promoters down-regulated in Spalax compared to mice in the hypoxia-responsive gene group. In this regard, one of the most important hypoxia-responsive genes is $m T O R$, which is a master regulator of cell growth control [37]. Previous studies have implicated downstream $m T O R$-regulated processes in the hallmarks of cancer: proliferative signaling, metabolic reprogramming, angiogenesis, and metastasis. We suggest that the down-regulated expression of $m T O R$ in the hypoxic conditions found in the tumor microenvironment may lead to declines in the metabolic rate and may be an adaptive mechanism that Spalax uses to resist cancer development.

Another very important barrier to cancer development is the immune system's tumor surveillance. In our analysis, compared to mice, Spalax displayed a stronger and more robust activation of innate immune response of the tumor suppressors responsible for tumor surveillance. The elevated expression of Tlr4, Ifngr1, Ifnar2, Stat1, and Irf1 that was revealed upon carcinogen treatment appeared to reflect a part of an integrated pathway reaction. Previous studies have shown that these innate immune genes are important players in tumor surveillance $[38,39]$. The expression of Stat1 in our study might have been the major exception because of its higher basal expression in the untreated control group. An earlier study reported that Stat 1 can inhibit the growth of benign and neoplastic cells by regulating the transcription and expression of several pro-apoptotic and anti-proliferative genes [40]. Irf1 is a transcriptional regulator and tumor suppressor that suppresses tumor cell growth and stimulates an immune response against tumor cells [41]. We believe that these changes in gene expression contribute to the Spalax-specific relative tolerance to the carcinogenic 3MCA compared to mice and might be a part of the layer of genes that enable Spalax's high cancer resistance.

As a potential additional defense, we found a stronger up-regulation of the immune system in Spalax compared to mice, especially of the innate immune-response tumor suppressors.

One of the major risk factors for cancer is aging. Spalax is known for its extreme longevity; the species can reach 20 years old in captivity, which is unusual for a mammal with such a small body mass. Since Spalax is also a solitary non-model organism that does not breed in captivity, the exact ages of specimens cannot be precisely determined, which could have been a confounding factor in our analysis. Due to this resistance, only four of the animals in our study developed a tumor, of two different phenotypes: granuloma and fibrosarcoma. These different factors created a high degree of variance in the data, since the samples were taken from only two different animals per tumor type and from animals of different sexes and ages. We addressed this variance in our study by rigorous normalization and filtering of the data.

\section{Conclusion}

We identified 25 genes in this study that we consider important for cancer development. Some of these genes are known to be related to cancer, while the roles of others are still unknown; we propose the latter as potential candidates for further cancer-resistance studies.

This study of the rare cases of failed cancer resistance in Spalax showed a tight network of genes that are responsible for the extracellular matrix remodeling. We consider these genes to be important for the difference between malignant and benign tumor development. This study has also pointed out several differences between Spalax and the model organism mice. The DNA repair genes of the Fanconi Anemia pathway were found to be especially important factors in cancer resistance.

\section{Materials \& methods \\ Animals and tissue extraction}

All animal protocols were approved by the University of Haifa Institutional Ethics Committee (Permit\# 193/ 10).The experimental design and the animals tested in the experiments are listed in Table 1. Spalax was captured in the field and kept in individual cages in the Animal Facility of the Institute of Evolution, University of Haifa. Mice were purchased from Harlan Laboratories (currently Envigo, Jerusalem, Israel). Twenty-Two Spalax and 12 mice $(\mathrm{C} 57 \mathrm{BL} / 6)$ were treated with 3MCA. All animals were kept at $21^{\circ}-23^{\circ} \mathrm{C}$ in a $12: 12$ light-dark cycle with free access to food and water. Untreated control Spalax animals were anesthetized with isoflurane when biopsies were taken ( $4 \%$ mixed in oxygen for the initial anesthesia; followed by $3 \%$ isoflurane flow for $20 \mathrm{~min}$ ), then animals were kept in the Animal Facility under veterinary observation for recovery. Animals with tumor growth and control mice received $10 \%$ isoflurane, continued for more than 2 min after breathing stopped, when the samples were taken.

The 3MCA treatment was done according to Manov et al.'s [10] paper. A single subcutaneous injection of 3MCA was administered to the left-flank of the neck of the Spalax and mice. When the tumor length reached about $2-3 \mathrm{~cm}$, it was completely removed. The most proximal $\sim 0.5 \mathrm{~cm}$ was harvested for RNA extraction, after pathological confirmation defining it as fibrosarcoma. For the control animals or the resistant Spalax individuals a similar sized neck muscle biopsy was removed for RNA extraction. The ages of the mice were 3 to 4 months. The age of Spalax cannot be accurately determined, as the species cannot be bred in captivity 
and are instead captured in the field; hence only their weight upon capture and the years they survive in captivity can serve as a reference of their age. Accordingly, we estimate the age of the treated animals to be between 2 years old to over 10 years old. Animals were checked for tumor growth once a week until such growth was palpable. The animals were then checked two to three times a week.

For histological examination, samples were fixed in $4 \%$ paraformaldehyde dissolved in PBS; they were then dehydrated in increasing concentrations of ethanol and embedded in paraffin. Form these blocks, five-micrometer sections were cut and stained with hematoxylin and eosin for microscopic histopathological examination to assess their tumorigenesis status.

\section{RNA extraction and sequencing}

RNA was extracted using the Qiagen miRNeasy Minikit according to the manufacturer's protocols. In short, frozen tissues were homogenized in QIAzol lysis reagent (Qiagen). After the addition of chloroform, the solution was vortexed and centrifuged. Ethanol was added to the aqueous phase and passed through a Qiagen cleanup column. Total RNA was eluted in 30 ul volumes. Quality was assessed on an Agilent bioanalyzer, and concentrations were determined by Qubit. Sequencing was performed by the Functional Genomics Unit of the W. M. Keck Center at the University of Illinois, USA. $1 \mu \mathrm{g}$ of total RNA was used to construct the libraries using the TruSeq Small RNA Sample Prep kit (Illumina). The strand-specific RNA-Seq libraries were prepared with Illumina's "TruSeq Stranded RNA Sample Prep" kit. The libraries were pooled in equimolar concentrations, and the pool was quantitated by $\mathrm{qPCR}$ and sequenced on one lane (small RNAs) or two lanes (RNA-Seq) for 101 cycles on a HiSeq2500 using a TruSeq SBS sequencing kit, version 4. Fastq files were generated and demultiplexed with bcl2fastq v1.8.4 conversion software (Illumina).

\section{RNA-Seq filtering and mapping}

Sequencing was performed by the Functional Genomics Unit of the W. M. Keck Center at the University of Illinois. The single-end RNA-Seq data were evaluated for their quality with Fastqc (www.bioinformatics.babraham.ac.uk). The reads were trimmed from adapters and regions of low quality using Trimmomatic 0.33 [42]. The filtered fastq files were stored in the Gene Expression Omnibus repository (GSE117501). To map the Spalax genome, we used the genome published by Fang et al. as a reference [8]. For mice, we used the reference genome published by NCBI. The reads were mapped to their respective genomes using TopHat2 [43] along standard parameters. Sorting and indexing were done using samtools [44], and the genes were counted using htseq-count [45]. The alignments were visualized using IGV $[46,47]$.

\section{Differential expression analysis}

Gene expression analysis was conducted using EdgeR [48] and DESeq2 [49]. Genes were considered differentially expressed if they had an adjusted $p$ value $\leq 0.05$. While both algorithms produced similar results, we used the consensus of both results as being differentially expressed. Functional annotation was done in $\mathrm{R}$ [50] using the packages topGO [51], KEGGREST [52], and biomarRt [53] for the GO [54] and KEGG [55] annotation. Gene descriptions and gene synonyms were acquired through Ensembl [56]. Gene relations were visualized using Cytoscape [46]. Additional gene information was gathered with GeneMANIA [11] and the web-based tool cBioPortal [57].

\section{microRNA sequencing, filtering and mapping}

Libraries were constructed using the TruSeq Small RNA Sample Prep kit (Illumina, CA, USA). The libraries were quantitated by qPCR and sequenced on one lane for 101 cycles from one end of the fragments on a HiSeq 4000 using a HiSeq 4000 sequencing kit, version 1. Fastq files were generated and demultiplexed with bcl2fastq v2.17.1.14 conversion software (Illumina). Adaptors were trimmed from the reads, which were then mapped using mirDeep [58]. Differential expression analysis was conducted using DESeq2 [49], while microRNA targets and regulators were taken from OncomiRDB [59].

\section{Additional file}

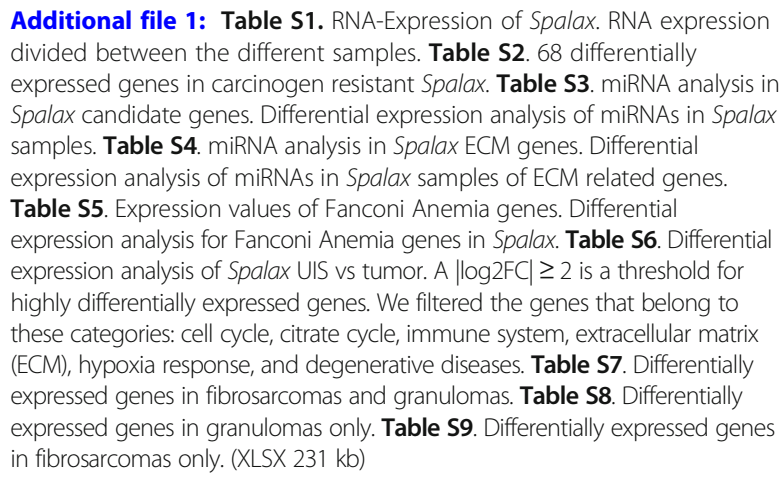

Additional file 1: Table S1. RNA-Expression of Spalax. RNA expression divided between the different samples. Table S2. 68 differentially expressed genes in carcinogen resistant Spalax. Table S3. miRNA analysis in Spalax candidate genes. Differential expression analysis of miRNAs in Spalax samples. Table S4. miRNA analysis in Spalax ECM genes. Differential expression analysis of miRNAs in Spalax samples of ECM related genes. Table S5. Expression values of Fanconi Anemia genes. Differential expression analysis for Fanconi Anemia genes in Spalax. Table S6. Differential expression analysis of Spalax UIS vs tumor. A $|\log 2 \mathrm{FC}| \geq 2$ is a threshold for highly differentially expressed genes. We filtered the genes that belong to these categories: cell cycle, citrate cycle, immune system, extracellular matrix (ECM), hypoxia response, and degenerative diseases. Table S7. Differentially expressed genes in fibrosarcomas and granulomas. Table S8. Differentially expressed genes in granulomas only. Table S9. Differentially expressed genes in fibrosarcomas only. (XLSX $231 \mathrm{~kb}$ )

\section{Abbreviations}

3MCS: 3-methylcholanthrene, a chemical carcinogen; DEG: Differetially expressed gene; EMC: Extracellular matrix; IS: Injected, and treated side of the animals neck; NME2: Nucleoside diphosphate alkylase 2; ROS: Reactive oxygen species; SSTR4: Somatostatin Receptor 4; TGF $\beta 1$ : Transforming growth factor $\beta 1$; UCP1: Mitochondrial uncoupling protein; UIS: Uninjected, and untreated side of the animals neck 


\section{Acknowledgments}

I.M. was supported by the Ministry of Immigrant Absorption and the Committee for Planning and Budgeting of the Council for Higher Education, Israel. We thank Dr. Vered Domankevich for valuable comments and suggestions. The authors also thank The Carver Biotechnology Center, headed by Dr. Mark Band, University of Illinois, for providing the sequencing services.

\section{Funding}

This work was supported by John Templeton Foundation [grant \#5305] and by the generous donation of the Kadas Family (UK). Funding bodies did not have a role in the design of the study and collection, analysis, and interpretation of data, neither in writing the manuscript.

\section{Availability of data and materials}

The data discussed in this publication have been deposited in NCBI's Gene Expression Omnibus and are accessible through GEO Series accession number GSE117501 (https://www.ncbi.nlm.nih.gov/geo/query/ acc.cgi?acc=GSE117501).

\section{Authors' contribution}

AA, IS and IM designed the study and performed the experiments. RA, AP and AK analysed the data. AP analysed the Fanconi Anemia pathway. AK contributed to the statistical design and evaluation of the data. RA and IS wrote the manuscript. All authors read and approved the final manuscript.

\section{Ethics approval}

All animal protocols were approved by the Institutional Ethics Committee (Permit\# 193/10), following the Guidelines for Use and Handling of Experimental Animals, the Council for Experimental Animals, Ministry of Health, Israel. Spalax is declared as unprotected pest in Israel; therefore, permission is not required to capture animals in the wild.

\section{Consent for publication}

Not Applicable.

\section{Competing interests}

The authors declare that they have no competing interests.

\section{Publisher's Note}

Springer Nature remains neutral with regard to jurisdictional claims in published maps and institutional affiliations.

\section{Received: 12 September 2018 Accepted: 26 December 2018} Published online: 08 January 2019

\section{References}

1. MacDonald D. The encyclopedia of mammals. Oxford: Oxford University Press; 2009.

2. Shams I, Avivi A, Nevo E. Oxygen and carbon dioxide fluctuations in burrows of subterranean blind mole rats indicate tolerance to hypoxichypercapnic stresses. Comp Biochem Physiol Part A Mol Integr Physiol. 2005:142(3):376-82.

3. Shams I, Avivi A, Nevo E. Hypoxic stress tolerance of the blind subterranean mole rat: expression of erythropoietin and hypoxia-inducible factor 1 alpha. Proc Natl Acad Sci U S A. 2004;101(26):9698-703.

4. Avivi A, Shams I, Joel A, Lache O, Levy AP, Nevo E. Increased blood vessel density provides the mole rat physiological tolerance to its hypoxic subterranean habitat. FASEB J. 2005;19(10):1314-6.

5. Malik A, Domankevich V, Lijuan H, Xiaodong F, Korol A, Avivi A, et al. Genome maintenance and bioenergetics of the long-lived hypoxia-tolerant and cancer-resistant blind mole rat, Spalax: a cross-species analysis of brain transcriptome. Sci Rep. 2016;6:38624.

6. Guzy RD, Schumacker PT. Oxygen sensing by mitochondria at complex III: the paradox of increased reactive oxygen species during hypoxia. Exp Physiol. 2006;91(5):807-19.

7. Schmidt H, Malik A, Bicker A, Poetzsch G, Avivi A, Shams I, et al. Hypoxia tolerance, longevity and cancer-resistance in the mole rat Spalax - a liver transcriptomics approach. Sci Rep. 2017;7(1):14348.
8. Fang X, Nevo E, Han L, Levanon EY, Zhao J, Avivi A, et al. Genome-wide adaptive complexes to underground stresses in blind mole rats Spalax. Nat Commun. 2014;5:3966

9. Nasser NJ, Avivi A, Shafat I, Edovitsky E, Zcharia E, llan N, et al. Alternatively spliced Spalax heparanase inhibits extracellular matrix degradation, tumor growth, and metastasis. Proc Natl Acad Sci U S A. 2009;106(7):2253-8.

10. Manov I, Hirsh M, lancu TC, Malik A, Sotnichenko N, Band M, et al. Pronounced cancer resistance in a subterranean rodent, the blind mole-rat, Spalax: in vivo and in vitro evidence. BMC Biol. 2013;11:91.

11. Warde-Farley D, Donaldson SL, Comes O, Zuberi K, Badrawi R, Chao P, et al. The GeneMANIA prediction server: biological network integration for gene prioritization and predicting gene function. Nucleic Acids Res. 2010; 38(suppl_2):W214-20.

12. Lattin JE, Schroder K, Su Al, Walker JR, Zhang J, Wiltshire T, et al. Expression analysis of $\mathrm{G}$ protein-coupled receptors in mouse macrophages. Immunome Res. 2008;4(1):5.

13. Su Al, Wiltshire T, Batalov S, Lapp H, Ching KA, Block D, et al. A gene atlas of the mouse and human protein-encoding transcriptomes. Proc Natl Acad Sci U S A. 2004;101(16):6062-7.

14. Bridge AJ, Babbitt PC, Smithers B, Huang X, Huang H, Lu S, et al. InterPro in 2017 - beyond protein family and domain annotations. 2016;

15. Tournier C. The 2 faces of JNK signaling in cancer. Genes Cancer. 2013;4(910):397-400.

16. Tomizawa M, Shinozaki F, Motoyoshi Y, Sugiyama T, Yamamoto S, Ishige N. CCAAT/enhancer-binding protein a decreases the viability of gastric cancer cells. Oncol Lett. 2017;13(6):4322-6.

17. Marastoni S, Andreuzzi E, Paulitti A, Colladel R, Pellicani R, Todaro F, et al. EMILIN2 down-modulates the Wnt signalling pathway and suppresses breast cancer cell growth and migration. J Pathol. 2014;232(4):391-404.

18. Ying $X$, Sun Y, He P. MicroRNA-137 inhibits BMP7 to enhance the epithelialmesenchymal transition of breast cancer cells. Oncotarget. 2017:8(11):18348-58.

19. Decock J, Hendrickx W, Vanleeuw U, Van Belle V, Van Huffel S, Christiaens MR, et al. Plasma MMP1 and MMP8 expression in breast cancer: protective role of MMP8 against lymph node metastasis. BMC Cancer. 2008:8:77.

20. Wang Y, Han E, Xing Q, Yan J, Arrington A, Wang C, et al. Baicalein upregulates DDIT4 expression which mediates MTOR inhibition and growth inhibition in cancer cells. Cancer Lett. 2015;358(2):170-9.

21. Egeblad M, Nakasone ES, Werb Z. Tumors as organs: complex tissues that interface with the entire organism. Dev Cell. 2010;18(6):884-901.

22. Kalluri R, Zeisberg M. Fibroblasts in cancer. Nature Reviews Cancer. 2006;6: 392-401.

23. Sanchez-Alvarez R, Martinez-Outschoorn UE, Lamb R, Hulit J, Howell A, Gandara R, et al. Mitochondrial dysfunction in breast cancer cells prevents tumor growth: understanding chemoprevention with metformin. Cell Cycle. 2013:12(1):172-82.

24. Porter RK. A new look at UCP 1. Biochimica et Biophysica Acta - Bioenergetics. 2006:1757:446-8.

25. Nedergaard J, Golozoubova V, Matthias A, Asadi A, Jacobsson A, Cannon B. UCP1: The only protein able to mediate adaptive non-shivering thermogenesis and metabolic inefficiency. Biochimica et Biophysica Acta Bioenergetics. 2001;1504:82-106.

26. Kim EB, Fang X, Fushan AA, Huang Z, Lobanov AV, Han L, et al. Genome sequencing reveals insights into physiology and longevity of the naked mole rat. Nature. 2011;479(7372):223-7.

27. Valle A, Oliver J, Roca P. Role of uncoupling proteins in cancer. Cancers. 2010;2:567-91.

28. Hennessy C, Henry JA, May FEB, Westley BR, Angus B, Lennard TWJ. Expression of the antimetastatic gene nm23 in human breast cancer: An association with good prognosis. J Natl Cancer Inst. 1991;83(4):281-5.

29. Guo R-S, Shi P-D, Zhou J, Chen Y-Y. Somatostatin receptors 3, 4 and 5 play important roles in gallbladder cancer. Asian Pac J Cancer Prev. 2013;14(7): 4071-5 Available from: http://www.ncbi.nlm.nih.gov/pubmed/23991955.

30. Lourenço AR, Coffer PJ. A tumor suppressor role for C/EBPa in solid tumors: more than fat and blood. Oncogene. 2017;36(37):5221.

31. Pickup MW, Mouw JK, Weaver VM. The extracellular matrix modulates the hallmarks of cancer. EMBO Rep. 2014:15(12):1243-53.

32. Israël M, Schwartz L. The metabolic advantage of tumor cells. Mol Cancer. 2011;10(1):70

33. Williams GH, Stoeber K. The cell cycle and cancer. J Pathol. 2012;226(2):352-64.

34. Jiang $X$, Shapiro DJ. The immune system and inflammation in breast cancer. Mol Cell Endocrinol. 2014;382(1):673-82. 
35. Ward AK, Mellor P, Smith SE, Kendall S, Just NA, Vizeacoumar FS, et al. Epigenetic silencing of CREB3L1 by DNA methylation is associated with high-grade metastatic breast cancers with poor prognosis and is prevalent in triple negative breast cancers. Breast Cancer Res. 2016;18(1):12.

36. Domankevich V, Eddini H, Odeh A, Shams I. Resistance to DNA damage and enhanced DNA repair capacity in the hypoxia-tolerant blind mole rat, Spalax. J Exp Biol. 2018;221(8):jeb174540. https://doi.org/10.1242/jeb.174540.

37. Rad E, Murray JT, Tee AR. Oncogenic Signalling through mechanistic target of rapamycin (mTOR): a driver of metabolic transformation and Cancer progression. Cancers (Basel). 2018;10(1):5.

38. Fang $H$, Ang $B, X u X$, Huang $X, W u Y$, Sun $Y$, et al. TLR4 is essential for dendritic cell activation and anti-tumor T-cell response enhancement by DAMPs released from chemically stressed cancer cells. Cell Mol Immunol. 2014;11(2):150-9.

39. Deng X, Wei W, Huang N, Shi Y, Huang M, Yan Y, et al. Tumor repressor gene chondroadherin oppose migration and proliferation in hepatocellular carcinoma and predicts a good survival. Oncotarget. 2017:8(36):60270.

40. Battle TE, Frank DA. The role of STATs in apoptosis. Curr Mol Med. 2002;2(4): 381-92.

41. Liu J, Guan X, Ma X. Interferon regulatory factor 1 is an essential and direct transcriptional activator for interferon \{gamma\}-induced RANTES/CCl5 expression in macrophages. J Biol Chem. 2005;280(26):24347-55.

42. Bolger AM, Lohse M, Usadel B. Trimmomatic: a flexible trimmer for Illumina sequence data. Bioinformatics. 2014;30(15):2114-20.

43. Kim D, Pertea G, Trapnell C, Pimentel H, Kelley R, Salzberg SL. TopHat2: accurate alignment of transcriptomes in the presence of insertions, deletions and gene fusions. Genome Biol. 2013;14(4):R36 Available from: http://genomebiology.com/2013/14/4/R36/abstract. Apr [cited 2015 Mar 2].

44. Li H, Handsaker B, Wysoker A, Fennell T, Ruan J, Homer N, et al. The Sequence Alignment/Map format and SAMtools. Bioinformatics. 2009;25(16): 2078-9 Available from: http://bioinformatics.oxfordjournals.org/content/25/ 16/2078. Aug [cited 2015 Mar 9].

45. Anders S, Pyl PT, Huber W. HTSeq: a Python framework to work with highthroughput sequencing data. Bioinformatics. 2015:31(2):166-9.

46. Cline MS, Smoot M, Cerami E, Kuchinsky A, Landys N, Workman C, et al. Integration of biological networks and gene expression data using Cytoscape. Nat Protoc. 2007;2(10):2366.

47. Thorvaldsdóttir H, Robinson JT, Mesirov JP. Integrative genomics viewer (IGV): high-performance genomics data visualization and exploration. Brief Bioinform. 2013;14(2):178-92.

48. Robinson MD, McCarthy DJ, Smyth GK. edgeR: a Bioconductor package for differential expression analysis of digital gene expression data. Bioinformatics. 2010;26(1):139-40.

49. Love Ml, Huber W, Anders S. Moderated estimation of fold change and dispersion for RNA-seq data with DESeq2. Genome Biol. 2014;15(12):550.

50. R Core Team. R: A Language and Environment for Statistical Computing. $R$ Foundation Stat Comput. 2015;1:409.

51. Alexa A, Rahnenfuhrer J. topGO: enrichment analysis for gene ontology. R Packag version. 2010;2(0).

52. Tenenbaum D. KEGGREST: Client-side REST access to KEGG. R Packag version. 2016;1(1).

53. Durinck S, Spellman PT, Birney E, Huber W. Mapping identifiers for the integration of genomic datasets with the R/Bioconductor package biomaRt. Nat Protoc. 2009:4(8):1184.

54. Consortium GO. Gene ontology consortium: going forward. Nucleic Acids Res. 2014;43(D1):D1049-56.

55. Kanehisa M, Furumichi M, Tanabe M, Sato Y, Morishima K. KEGG: new perspectives on genomes, pathways, diseases and drugs. Nucleic Acids Res. 2016;45(D1):D353-61.

56. Zerbino DR, Achuthan P, Akanni W, Amode MR, Barrell D, Bhai J, et al. Ensembl 2018. Nucleic Acids Res. 2017:46(D1):D754-61.

57. Gao J, Aksoy BA, Dogrusoz U, Dresdner G, Gross B, Sumer SO, et al. Integrative analysis of complex cancer genomics and clinical profiles using the cBioPortal. Sci Signal. 2013;6(269):pl1.

58. An J, Lai J, Lehman ML, Nelson CC. miRDeep*: an integrated application tool for miRNA identification from RNA sequencing data. Nucleic Acids Res. 2012;41(2):727-37.

59. Wang D, Gu J, Wang T, Ding Z. OncomiRDB: a database for the experimentally verified oncogenic and tumor-suppressive microRNAs. Bioinformatics. 2014;30(15):2237-8.
60. Rochette A, Boufaied N, Scarlata E, Hamel L, Brimo F, Whitaker HC, et al. Asporin is a stromally expressed marker associated with prostate cancer progression. Br J Cancer. 2017;116(6):775.

61. dos Reis ST, Pontes-Júnior J, Antunes AA, de Sousa-Canavez JM, Abe DK, da Cruz JAS, et al. Tgf- $\beta 1$ expression as a biomarker of poor prognosis in prostate cancer. Clinics. 2011;66(7):1143-7.

62. Rucci N, Capulli M, Olstad OK, Önnerfjord P, Tillgren V, Gautvik KM, et al. The a $2 \beta 1$ binding domain of chondroadherin inhibits breast cancer-induced bone metastases and impairs primary tumour growth: a preclinical study. Cancer Lett. 2015;358(1):67-75.

63. Tang J-C, Liu J-H, Liu X-L, Liang X, Cai X-J. Effect of fibulin-5 on adhesion, migration and invasion of hepatocellular carcinoma cells via an integrindependent mechanism. World J Gastroenterol WJG. 2015;21(39):11127.

64. Wang M, Topalovski M, Toombs JE, Wright CM, Moore ZR, Boothman DA, et al. Fibulin-5 blocks microenvironmental ROS in pancreatic cancer. Cancer Res. 2015;75(23):5058-69.

65. Coulson-Thomas VJ, Coulson-Thomas YM, Gesteira TF, de Paula CA, Carneiro $C R$, Ortiz V, et al. Lumican expression, localization and antitumor activity in prostate cancer. Exp Cell Res. 2013;319(7):967-81.

66. Rogler A, Kendziorra E, Giedl J, Stoehr C, Taubert H, Goebell PJ, et al. Functional analyses and prognostic significance of SFRP1 expression in bladder cancer. J Cancer Res Clin Oncol. 2015:141(10):1779-90.

67. Pellegata NS, Dieguez-Lucena JL, Joensuu T, Lau S, Montgomery KT, Krahe $\mathrm{R}$, et al. Mutations in KERA, encoding keratocan, cause cornea plana. Nat Genet. 2000;25(1):91-5.

68. Wendel M, Sommarin $Y$, Heinegård D. Bone matrix proteins: isolation and characterization of a novel cell-binding keratan sulfate proteoglycan (osteoadherin) from bovine bone. J Cell Biol. 1998;141(3):839-47.

69. Livingstone C. IGF2 and cancer. Endocr Relat Cancer. 2013;20(6):R321-39.

70. Brouwer-Visser J, Huang GS. IGF2 signaling and regulation in cancer. Cytokine Growth Factor Rev. 2015;26(3):371-7.

71. Koschmieder S, Halmos B, Levantini E, Tenen DG. Dysregulation of the C/EBPa differentiation pathway in human cancer. J Clin Oncol. 2008;27(4):619-28.

72. Vleugel MM, Greijer AE, Bos R, van der Wall E, van Diest PJ. C-Jun activation is associated with proliferation and angiogenesis in invasive breast cancer. Hum Pathol. 2006;37(6):668-74

73. Kappelmann M, Bosserhoff A, Kuphal S. AP-1/C-Jun transcription factors: regulation and function in malignant melanoma. Eur J Cell Biol. 2014;93(12):76-81.

\section{Ready to submit your research? Choose BMC and benefit from:}

- fast, convenient online submission

- thorough peer review by experienced researchers in your field

- rapid publication on acceptance

- support for research data, including large and complex data types

- gold Open Access which fosters wider collaboration and increased citations

- maximum visibility for your research: over $100 \mathrm{M}$ website views per year

At $\mathrm{BMC}$, research is always in progress.

Learn more biomedcentral.com/submissions 